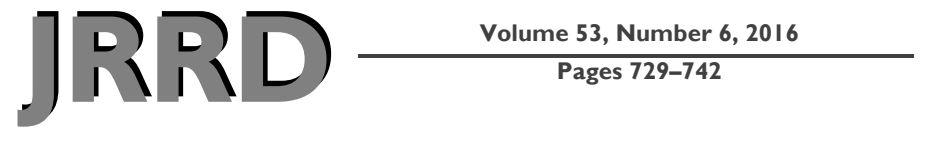

\section{Coping with tinnitus}

\author{
Erin Martz, PhD, CRC; ${ }^{1-2 *}$ James A. Henry, PhD ${ }^{1,3}$ \\ ${ }^{1}$ National Center for Rehabilitative Auditory Research, Department of Veterans Affairs Portland Health Care System, \\ Portland, OR; ${ }^{2}$ Rehability, Beaverton, OR; ${ }^{3}$ Department of Otolaryngology/Head and Neck Surgery, Oregon Health \& \\ Science University, Portland, OR
}

\begin{abstract}
This narrative article on coping with tinnitus has four primary objectives. First, theoretical perspectives about defining and categorizing coping are discussed. Second, an overview of the empirical research on coping with tinnitus is provided, focusing on how coping with tinnitus has been measured and on the trends that were found in research on coping with tinnitus. Third, the problems related to the current state of research on coping with tinnitus are highlighted. Fourth, suggestions are provided on ways that researchers can improve research on coping with tinnitus.
\end{abstract}

Key words: adaptation, auditory rehabilitation, chronic health condition, coping, disability, impairment, psychometrics, rehabilitation, tinnitus, Veterans.

\section{INTRODUCTION}

Having a chronic impairment can be stressful and can trigger multiple psychological reactions related to loss of functioning, physical discomfort, and unwanted change [1-3]. Research indicates that individuals with chronic impairments and disabilities may be more vulnerable than the general population to the development of negative affective states such as anxiety, depression, and distress [4-7]. Researchers have observed this trend among individuals with tinnitus [8-10], which is an impairment that involves ringing or hissing in the ears that is not produced by external sound. In response to the stress triggered by the onset or continued existence of a chronic impairment or disability, individuals may use various coping strategies [11]. In the present article, the published research on coping with tinnitus is reviewed and suggestions are provided for future studies on coping with tinnitus.

\section{WHY STUDY COPING WITH TINNITUS?}

The first reason to study coping with tinnitus is that tinnitus is experienced by a remarkable number of individuals. Epidemiological estimates indicate a prevalence of tinnitus between 4.4 and 15.1 percent across adult population studies and across different countries (see Møller Table 5.1 [12]). Further, in each of their annual reports since 2007, the Veterans Benefits Administration reported that tinnitus was the most prevalent service-connected

\footnotetext{
Abbreviations: $\mathrm{CBT}=$ cognitive behavioral therapy, $\mathrm{CET}=$ Coping Effectiveness Training, PTM = Progressive Tinnitus Management, $\mathrm{RCT}=$ randomized controlled trial, TCQ $=$ Tinnitus Coping Questionnaire, TCSQ = Tinnitus Coping Strategy Questionnaire, TCT = Tinnitus Coping Training, TFI = Tinnitus Functional Index, TRQ = Tinnitus Reaction Questionnaire, TRT $=$ Tinnitus Retraining Therapy, VA = Department of Veterans Affairs.

*Address all correspondence to Erin Martz, PhD, CRC; National Center for Rehabilitative Auditory Research, VA Portland Health Care System, Bldg 6, Rm 114A, 3710 SW US Veterans Hospital Rd, Portland, OR 97239; 503-2208262, ext 56006. Email: Erin.Martz@va.gov http://dx.doi.org/10.1682/JRRD.2015.09.0176
} 
disability among U.S. Veterans receiving compensation. Given the prevalence of tinnitus in the general and Veteran populations, as well as its associated economic costs (e.g., costs of treatment and disability compensation), greater attention and understanding are needed regarding how individuals cope with tinnitus. Tinnitus-related coping should be an essential psychological construct to research, not only because of the prevalence of tinnitus and its economic costs but also because most types of tinnitus are not curable at this time and, as such, may be a continuous source of stress for individuals.

The second reason to study coping is that a coping intervention may be more useful than other types of psychological interventions for tinnitus because coping interventions do not attempt to change individuals' views about the source of stress. Some interventions for tinnitus attempt to change the perception of tinnitus from a negative stimulus to a neutral stimulus (e.g., Tinnitus Retraining Therapy [TRT] [13-14]) or to alter the cognitive distortions associated with having tinnitus (e.g., cognitive behavioral therapy [CBT] [15-17]). Coping research suggests that trying to change an individual's perspective that an event is a negative or aversive stimulus does not have to be the focus of a coping intervention. Instead, a coping intervention would focus on helping individuals select a coping strategy that effectively reduces the effect of the negative stimuli on an individual's life. Thus, instead of focusing on reframing the source of stress, coping interventions would allow individuals to view stressful stimuli, such as tinnitus, as a negative stimulus or an "unchangeable stressor"-meaning that it cannot be altered by the individual [18].

Coping interventions would teach individuals about the range of coping strategies available for managing a variety of stressful stimuli and, in the context of tinnitus, how to strategically cope with the fluctuating symptoms of tinnitus. A wealth of empirical research indicates that the effective use of coping can help to decrease negative psychological responses to aversive stimuli (i.e., stress) across a wide range of populations [11,19]. Thus, teaching individuals to better cope with their tinnitus, while acknowledging that tinnitus can be very stressful to experience, may help them to decrease their negative affective responses.

\section{DEFINING AND CATEGORIZING COPING}

\section{Definitions and Taxonomies of Coping}

Coping is triggered in the presence of stress and, fundamentally, can be regarded as a person's efforts to manage stress. Lazarus and Folkman's transactional theory on stress and coping [20] was adopted by many researchers as a cornerstone for their coping research. Lazarus and Folkman defined coping as the "constantly changing cognitive and behavioral efforts to manage specific external and/or internal demands that are appraised as taxing or exceeding the resources of the person" [20 (p. 141)]. In the context of chronic impairments such as tinnitus, coping can be defined as the cognitive, affective, and behavioral attempts to reduce stress related to a disability or impairment for which an individual does not necessarily have automatic, adaptive responses [20-21]. Other researchers proposed that coping also can be viewed as a psychologically normal response in circumstances that require special psychosocial efforts or are unusually taxing [22].

Folkman and Moskowitz pointed out that individuals' coping levels should not be regarded as indicative of mastery or resolution of a stressor given that in some situations involving chronic stress (e.g., impairments or disabilities), the stress involves "chronic, inherently unresolvable situations and conditions" [23 (p. 754)]. Thus, coping should not be viewed as resolving stressbut managing stress - especially in the context of chronic impairments. Littleton et al. noted that individuals with chronic impairments "may have to 'cycle' through using [coping] approach strategies multiple times before these strategies result in the individual . . reducing its effects to a manageable level" [24 (p. 985)]. Thus, successful coping does not mean that stress or the negative stimulus is extinguished, removed, or changed into a neutral or positive stimulus; instead, effective coping reflects the individual's ability to respond to stress to decrease the individual's negative affectivity (i.e., negative psychological responses).

Regarding the classification of types of coping, over the past few decades researchers have provided a variety of taxonomies to categorize coping strategies. Given the broad range of theoretical perspectives on how to define stress and the clinical and empirical observations about the ways individuals cope with stress, taxonomies were used to bring order and clarity to the study of coping. One approach was to categorize the dimensions, groups, or families of coping strategies. Lazarus and Folkman's 
1984 model contained a dichotic taxonomy of coping strategies, for which responses fell into two broad, theory-based categories: (1) problem-solving coping, which involves strategies that attempt to change what is causing stress (e.g., action-oriented, planning, and goal-focused strategies); and (2) emotion-focused coping, which involves strategies that endeavor to manage or reduce the negative emotional reactions to stress (e.g., relaxation exercises, meditating, praying, acceptance, use of humor, avoidance, denial, crying, blaming, and distraction techniques) [20]. Lazarus and Folkman's dichotic taxonomy of coping strategies was challenged by numerous researchers [25-26]. Folkman and Moskowitz later considered other types of coping taxonomies with additional categories (e.g., social support coping, meaning-focused coping, and religious coping) [23].

Krohne proposed a coping taxonomy involving a hierarchical framework that spanned from broad "macroanalytic" coping dimensions to specific "micro-analytic" coping behaviors [27]. The three main categories were (1) the macro-analytic level of theoretical abstraction, including coping dimensions, dispositions, or axes, such as engagement versus disengagement coping [28] or approach/vigilance/attention versus avoidance coping dimensions [29-31]; (2) a midrange level of abstraction that reflected conceptually coherent groups of coping reactions or strategies (e.g., denial, confrontation, distancing, seeking social support) that could be assessed by numerous multidimensional coping instruments; and (3) the lower-level or micro-analytic range of abstraction that involved coping behaviors or reactions and that reflected situationally influenced, specific coping behaviors that also could be assessed by numerous multidimensional coping instruments.

As coping research evolves, coping researchers continue to be challenged in understanding types of coping strategies through the use of taxonomies. There is a huge selection of possible coping taxonomies. For example, Skinner and colleagues analyzed around 100 systems for categorizing coping strategies [32]. They summarized the taxonomies as including the lower-order (e.g., subordinate or "inductive bottom-up") approaches and higherorder (e.g., superordinate or "deductive top-down") approaches to categorizing coping strategies [32].

\section{Coping Versus Adaptation}

A psychological concept that is similar to coping and is sometimes used interchangeably in tinnitus research studies is the construct of adaptation. Both coping and adaptation can be used to represent the psychosocial reactions that individuals experience related to the stress of a chronic impairment or disability. However, the two concepts should be distinguished, in that coping reflects the more immediate or proximal psychological reactions, while adaptation refers to the longer-term or distal psychological processes of adjusting to an impairment or disability $[1,21,33]$. As Holahan et al. stated, coping is "a stabilizing factor" that can help individuals maintain psychosocial adaptation during stressful periods. It encompasses cognitive and behavioral efforts to reduce or eliminate stressful conditions and associated emotional distress" [34 (p. 25)]. Thus, coping can be viewed as the strategies individuals use on an hourly or daily basis to manage stress, which can facilitate the longer-term process of adaptation to impairments and disabilities.

However, not all researchers make clear conceptual distinctions between coping and adaptation. For example, the term "adaptive coping" is used to indicate that the coping strategy is effective in reducing an individual's distress, while "maladaptive coping" or "nonadaptive coping" is used to reflect that the coping strategy is ineffective for stress reduction [23]. If viewed as reflective of the outcome of a coping strategy for a specific stressor, the adaptive versus nonadaptive coping distinction appears to be straightforward and to be an appropriate hybrid term using coping and adaptation terms. But the conceptual clarity becomes attenuated if researchers or clinicians attempt to categorize some coping strategies as always unhealthy or nonadaptive. For example, the coping strategy of crying can reduce one's stress levels (i.e., adaptive coping), but it can also be viewed as an expression of negative affectivity (i.e., nonadaptive coping).

When studying coping strategies in the context of an unalterable stressor such as tinnitus, it is important to note that different kinds of coping may be needed when an individual has an incurable physical impairment. An individual may use emotion-focused coping strategies to reduce stress levels and may use problem-solving coping to take action to reduce the stress created by the impairment. Thus, an individual with a chronic impairment such as tinnitus may need to use both types of coping strategies and both types may be considered adaptive; yet, only one type (problem-solving coping) may actually resolve the stress, while the other type (emotion-focused coping) may help an individual to manage or reduce the stress. This illustrates why it is not useful to categorize 
certain coping strategies as always adaptive or nonadaptive. Commenting on the contextual and fluctuating nature of coping with medical issues, Lazarus wrote, "What a person does to cope depends on the context in which the disease occurs, and this will change over time because what is attended to, and the threats themselves, also change" [35 (p. 236)]. Livneh also noted that coping with stress caused by impairments (e.g., tinnitus) should involve the fluid use of different types of coping strategies in order to meet changing demands and types of stressors that vary over time [36].

\section{Temporal and Matching Aspects of Coping Strategies}

Many studies have focused on two variables that influence the effectiveness of coping strategies in reducing stress. These two aspects are the timing of its usage, or the temporal aspect of coping [36], and matching the type of stress with the type of coping strategy selected [37].

Regarding the temporal aspects of coping, Suls and Fletcher's meta-analysis of empirical coping research supports the concept that coping has a temporal element that is related to its effectiveness in reducing stress levels [31]. Their meta-analysis examined two groups or families of coping strategies: (1) avoidant coping, which was defined as "a strategy that focuses attention away from either the source of stress or away from one's psychological/somatic reactions to the stressor"; and (2) nonavoidant coping (sometimes called approach coping), which was defined as a strategy for which "the respondent focuses attention on the source of stress and/or one's psychological/somatic reactions to the stressor" [31 (p. 250)]. Suls and Fletcher compared the efficacy of these two primary groups of coping strategies for reducing pain, stress, and anxiety. The results indicated that across studies, avoidant coping was effective in reducing stress soon after the onset of a stressor (up to a $2 \mathrm{wk}$ period). The approach, nonavoidant, or attention coping strategies were related to better long-term outcomes, such as more positive adaptation over time, which Suls and Fletcher explained as consistent with Lazarus and Folkman's [20] or Horowitz's [38] theories on coping with trauma. Those theorists described that right after the onset of a stressor, attention processes may be overwhelmed, but as individuals gradually adjust to information related to the stressor, they become more able to pay attention to the stressor and "attentional strategies become more beneficial" [31 (p. 279)].
A more recent meta-analysis also suggested that there is a temporal component to coping. Littleton et al. conducted a meta-analysis on coping strategies among individuals who experienced interpersonal violence and severe injury [24]. They found a significant, positive association between overall avoidance coping and distress. Further, they found that time moderated the inverse association between distress and approach coping (i.e., coping strategies that directly address stress), indicating that this association was stronger when more time had passed since the traumatic event. This supports the findings of Suls and Fletcher's meta-analysis that approach coping was more effective than avoidance coping at reducing stress as the time since its onset increased.

Regarding the need to match the type of stress with the most beneficial coping strategy, an important clarification was made in the debate about the effectiveness of coping strategies by Chesney et al. [37]. These researchers emphasized the importance of matching the type of coping strategy used with the type of stressor; which was called the "goodness of fit" of coping strategies [20]. Chesney et al.'s idea was that ineffective coping occurs when the coping strategy is not well matched with the type of stressor, such as "when people respond to changeable stressors with emotion-focused coping strategies or when people respond to unchangeable stressors with problem-focused coping strategies" (i.e., they try to change the unalterable stressor) $[37$ (p. 1038)]. These researchers shifted the emphasis from a focus on the effectiveness of the outcome (i.e., whether a certain type of coping strategy reduced stress) to the contextual process of selecting the appropriate type of coping strategy according to whether the stressor itself was changeable or unalterable. Chesney and colleagues noted that outcomes improve with a better fit between the type of stress and the coping strategy selected to address the stress: "When there is a poor fit, people experience more psychological symptoms than when there is a better fit" [37 (p. 1038, emphasis added)]. Their ideas suggest that if an individual attempted to use problem-solving coping with an unchangeable stressor (e.g., trying to find a cure for one's own tinnitus), then this coping strategy most likely would be ineffective and may lead to greater stress and negative psychological reactions. In summary, research suggests that certain types of coping are more effective when considering both the fit/match of the stressor with the coping strategy and the temporal factors of coping, both of which may influence the coping effectiveness. 
EMPIRICAL STUDIES ON COPING WITH TINNITUS: TRENDS IN THE RESEARCH

\section{Concepts}

Before reviewing the empirical literature on coping with tinnitus, one caveat needs to be mentioned. When analyzing the empirical literature on coping with tinnitus, it becomes evident that some researchers studying psychosocial responses to tinnitus have interchangeably used the terms coping and adaptation (in addition to other synonyms, such as accepting or adjusting) in their articles without clearly distinguishing the concepts [39-44]. Further, because a variety of definitions of coping have been used in the context of tinnitus, this lack of definitional clarity has resulted in a fragmented understanding of the empirical data and, thus, of the patterns and correlates of tinnitus-related coping.

\section{Descriptive Studies}

Sullivan et al. compared coping in a group of 40 individuals with tinnitus to a group of 14 individuals with hearing impairments [45]. They used the revised Ways of Coping Checklist [46]. They found that the tinnitus group utilized significantly more avoidant coping strategies than the hearing loss group. Further, after dividing the tinnitus group into depressed versus nondepressed groups based on their scores on the Symptom Checklist-90 [47], these researchers found that the depressed group of individuals with tinnitus used significantly fewer problemsolving coping strategies than the nondepressed individuals with tinnitus.

Budd and Pugh focused on directly examining coping with tinnitus and published two articles in 1996. One article provided information about their Tinnitus Coping Style Questionnaire based on a sample of 116 individuals with tinnitus [41]. Their factor analysis suggested that the Tinnitus Coping Style Questionnaire was composed of three factors: (1) maladaptive coping (i.e., nonadaptive coping), such as fantasies about not having tinnitus, complaining about tinnitus, and having catastrophic thoughts about tinnitus; (2) effective coping, such as using positive self-talk, switching one's attention, and participating in activities to reduce attention on tinnitus; and (3) passive coping, such as avoidance of tinnitus or trying to mask tinnitus. Further, both the maladaptive and the passive coping styles (i.e., coping factors) were significantly and positively correlated with anxiety, depression, and reported tinnitus severity, while the effective coping style was not significantly correlated with depression or reported tinnitus severity but was significantly and inversely correlated with anxiety. In a second article published in 1996, Budd and Pugh reexamined the factor structure of the Tinnitus Coping Style Questionnaire in a different sample of 108 individuals with tinnitus and found that the results supported a two-factor (not threefactor) structure of effective and maladaptive coping styles, thereby eliminating the passive coping style [40]. In this study, only maladaptive coping was significantly correlated with tinnitus severity, anxiety, and depression.

Bartels et al. utilized Budd and Pugh's Tinnitus Coping Style Questionnaire to examine the association of coping strategies with anxiety and depression levels among 265 individuals with tinnitus [48]. They adopted Budd and Pugh's two-factor structure, namely effective and maladaptive coping, as well as the cutoff scores in the Hospital Anxiety and Depression Scale [49] to create four groups (depression only, anxiety only, depression plus anxiety, or no symptoms [i.e., symptoms were below clinical thresholds]). Their findings indicated that when comparing groups according to depression only, anxiety only, depression plus anxiety, or no symptoms on the two coping factors, only maladaptive coping (i.e., nonadaptive coping) showed significant differences between groups. The no symptoms group exhibited the lowest maladaptive coping scores, and the depression plus anxiety group reflected the highest maladaptive coping scores.

Another coping-with-tinnitus instrument, the Tinnitus Coping Strategy Questionnaire (TCSQ), was developed by Henry and Wilson [42] based on Henry's 1992 doctoral dissertation. Their title resulted in the same acronym as Budd and Pugh's coping instrument, the Tinnitus Coping Style Questionnaire, which might create confusion in certain research circumstances. Henry and Wilson's TCSQ consisted of 33 items, each of which was rated twice by participants, the first time on the frequency that they had been using a specific coping strategy (TCSQ Frequency) and the second time on how helpful they found its use (TCSQ Benefits), creating two subscales. In the second study in the same article, Henry and Wilson [42] divided their sample of 81 individuals with tinnitus by their scores on the Tinnitus Reaction Questionnaire (TRQ) [50], naming them high-distress ( $\geq 17$ points on the TRQ) and low-distress groups $(<17$ points on the TRQ). They analyzed whether there were significant differences between high-distress and low-distress groups, finding no significant differences in distress between these two groups on 
either the TCSQ Frequency or Benefits subscales. This finding suggests that more psychometric analyses needed to be performed on Henry and Wilson's TCSQ scale because their analysis did not distinguish between the high- and low-distress groups. Further, because results of a factor analysis of the TCSQ items were not reported, it is unclear what types of coping (e.g., problem-solving, emotion-focused coping) that the items of this questionnaire assessed; instead, only the subscales of frequency of use and the helpfulness of the coping strategies were reported, which is one major limitation of Henry and Wilson's TCSQ.

Andersson et al. [39] examined coping among 157 individuals with tinnitus using Henry and Wilson's TCSQ and its association with tinnitus-related distress as reported by the TRQ [50]. Their results indicated significant, positive zero-order correlations between coping strategies (i.e., both TCSQ subscales) and tinnitus-related distress (measured by the TRQ), as well as a multiple regression for which TCSQ Frequency was a significant predictor of tinnitus-related distress. Their discussion contained multiple statements interpreting the positive association between more frequent use of coping and greater distress as suggesting "a possible negative role of coping strategies in relation to tinnitus distress" [39 (p. 56)] and "coping strategies might not be useful and may even be associated with more distress" [39 (p. 58)]. However, they did acknowledge that "it might be important to help patients distinguish between useless attempts to try to control something that cannot be controlled (as often is the case with loudness of tinnitus)" [39 (p. 58)]. Andersson and colleagues' empirical findings were not unusual, in view of Folkman and Moskowitz's statement that in a majority of studies the use of emotion-focused types of coping have been found to be related to greater distress [23]. Folkman and Moskowitz suggested that such findings may be artifacts of the means by which studies were conducted (i.e., measurement issues), because emotion-focused coping involves "actively processing and expressing emotion" [23 (p. 761)]. An additional issue related to Andersson et al.'s study was that the research did not include a factor analysis of the TCSQ with the data from their sample, and consequently, information about the types of coping strategies that predicted distress was not available in their study. A factor analysis of the TCSQ may have provided a different set of items than the two subscales (TCSQ Frequency and Benefits) and, consequently, may have provided different results in the correlational and regression analyses.

\section{Psychological Interventions for Tinnitus}

The unchangeable nature of tinnitus itself necessitates that people who experience bothersome tinnitus have to learn new coping skills. While individuals may naturally or intuitively use coping strategies to reduce their stress, one skill that can be helpful to individuals with tinnitus is teaching them how to distinguish between what is modifiable (e.g., enrich their sound environments in order to alter their primary focus on tinnitus) and what tinnitus-related issues are unmodifiable (e.g., the fact of having tinnitus). Coping Effectiveness Training (CET) is one intervention that specifically teaches individuals to distinguish between changeable and unchangeable stress and how to select the most appropriate type of coping strategy according to the type of stress [18]. However, because no empirical interventions have been published using CET among individuals with tinnitus to date, this intervention will be discussed in a later section.

While a variety of clinical interventions have been developed over several decades to address the psychosocial sequelae associated with tinnitus, there is a paucity of psychological interventions that not only teach coping skills but also assess coping strategies using psychometrically valid coping instruments in the context of tinnitus. The next section will review the trends observed in metaanalyses on tinnitus interventions, specifically those related to CBT interventions, in order to better understand the general trends in tinnitus intervention research; the subsequent section will focus on interventions that have purported to teach coping skills to individuals with tinnitus, yet have not adequately assessed coping strategies in the reported results.

\section{Meta-Analyses of Psychological Interventions for Tinnitus}

Numerous meta-analyses have been conducted on the efficacy of psychological treatments for tinnitus. One of the first meta-analyses, conducted by Andersson and Lyttkens, examined the results of 18 empirical studies that included CBT, relaxation, hypnosis, biofeedback, educational sessions, and problem-solving interventions [51]. They found that CBT interventions demonstrated specific types of efficacy; that is, CBT was more effective in reducing participants' ratings of tinnitus annoyance than tinnitus loudness. A medium effect size of 0.48 
was found for CBT on negative affect (i.e., depression and anxiety).

Martinez-Devesa and colleagues provided a Cochrane review on CBT interventions for tinnitus and found that across the studies they analyzed, CBT decreased tinnitus severity (i.e., subjective loudness of tinnitus) and depression while increasing quality of life [52]. Hesser and colleagues' meta-analysis on the efficacy of CBT interventions for tinnitus indicated that CBT was moderately effective in reducing tinnitus-related annoyance and distress and improving mood (anxiety and depression) [53]. According to these researchers, the data indicated that the effects of $10 \mathrm{CBT}$ interventions were robust over a 3 to 18 mo time period.

Hoare and colleagues' meta-analysis examined data from 28 randomized controlled trials (RCTs) for tinnitus management that included interventions for adults with tinnitus containing validated outcome instruments and at least one other group (no treatment or a comparative treatment group) [54]. According to Hoare et al., only the CBT RCTs were comparable. Findings indicated that across studies, CBT did not appear to be effective in reducing depression and anxiety among individuals with tinnitus, but the results indicated that CBT was associated with reductions in self-reported tinnitus severity. Hesser et al. noted that one issue related to the challenge of comparing the results of CBT interventions was that researchers may include a range of techniques and methods in CBT intervention [53]. The main strategies typically included in CBT interventions were focusing on altering cognitive distortions, using positive imagery, and employing stress management techniques.

\section{Coping Interventions for Tinnitus}

Henry and Wilson conducted an RCT of 60 individuals with tinnitus [55]. They compared three groups: (1) a treatment group involving a cognitive educational program that consisted of "cognitive coping skills training" (including attention diversion, imagery training, and thought-management skills), which was taught in combination with tinnitus education; (2) an education-only treatment group; and (3) a wait-list control group. Coping was assessed by the two subscales in their TCSQ instrument. The results indicated that the two treatment groups, but not the control group, had significant improvements on both the TCSQ Frequency and TCSQ Benefits subscales. However, there were no significant differences between the two treatment groups on the two coping subscales nor were the findings between the two treatments and the control group still significant at a 12 mo follow-up.

While Kröner-Herwig and colleagues did not measure coping directly when they first published their research on a 10 -session intervention using Tinnitus Coping Training (TCT) [56], they corrected that oversight by assessing coping in a later intervention study that used a modified 11-session TCT [57]. In their 2003 article, coping was measured using four items taken from Frenzel's Tinnitus Coping Questionnaire (TCQ) [58], which was published in German; details were not provided on the psychometrics of these four items nor of the TCQ. The results of Kröner-Herwig et al.'s 2003 study indicated that the group that received TCT exhibited significant improvement in coping compared with two minimal contact groups and a wait-list control group [57].

Zachriat and Kröner-Herwig conducted a longitudinal study consisting of two treatment groups of either an 11-session TCT group or a 5-session habituation group and a control group that received one session of education only [43]. Coping was measured by Frenzel's TCQ [58]. The two treatment groups exhibited significantly less tinnitus-related disability than the control group. The use of coping strategies was significantly greater in both the TCT group compared with the habituation group and the habituation group compared with the educational control group. This study also reflected the previously noted problem with using the TCQ; i.e., no details were given on the psychometrics of the instrument and no factor analysis was conducted to examine the coping patterns that were unique to the sample.

\section{TINNITUS RESEARCH RELATED TO COPING: COMMON PROBLEMS}

Although numerous researchers have realized that coping is an important issue to consider in the context of tinnitus, their studies have been complicated by several issues. The first is the aforementioned lack of conceptual clarity about the definition of coping as well as the lack of a definitional distinction between coping and adaptation.

A second common problem with research purportedly on coping with tinnitus is that the term "coping" may be cited in the title or body of the article without the concomitant measurement of coping variables or coping outcomes $[56,59]$. A related issue is that coping is described as an effect of a tinnitus intervention without researchers 
assessing coping with a coping instrument. Examples of this issue can be found in Scott et al.'s "self-control technique" intervention [60], Henry and Wilson's and Andersson and Kaldo's CBT interventions [55,61], and Wise et al.'s study that compared a tinnitus-management therapy group to a problem-solving group intervention [62]. Further examples are studies that contain the word "coping" in the title of a tinnitus intervention, such as "tinnitus coping training" [56] or "tinnitus coping therapy" [63], but did not actually measure coping variables in the research.

A third issue across many studies is that some intervention studies that purportedly bolstered coping used proxy measures to assess coping [56,60,64-67]. Instead of directly measuring coping, researchers imputed coping by observing changes in negative affectivity (e.g., decreases in depression and anxiety) [56,60,63-67]. Thus, coping was not measured directly using psychometrically sound coping instruments; rather, coping changes were represented by indirect observations of decreases in anxiety or depression scales.

A fourth major issue with tinnitus-related coping studies is that, of the studies that included some form of coping measurement, most did not utilize a psychometrically sound coping instrument with published validity and reliability. For example, the Tinnitus Coping Style Questionnaire by Budd and Pugh had an unstable factor structure [40-41], yet some researchers [48] still used it as part of their analyses and failed to examine the structure of the coping factors in their particular sample. A related issue is that other research studies used coping instruments with unpublished psychometrics, such as the Strategies for Handling Stress questionnaire used by Hallberg et al. [68] or the Impact Psychologique de L'acouphène by Philippot and colleagues [69]. Without publically available psychometrics, it is difficult to know whether the coping instrument is psychometrically sound.

A fifth issue is that while some researchers have used a psychometrically sound instrument in their research, their choice of a specific instrument to represent the construct of coping reflected an error related to construct validity. For example, the Tinnitus Functional Index (TFI) [70] is a psychometrically sound instrument that contains only one item: "How easy was it for you to cope with your tinnitus?" If researchers were to use this instrument, they would have no information about the type of coping strategy used. The TFI scale as a whole should not be used to reflect, represent, or imply coping.

\section{Suggestions for Tinnitus Research Involving Coping}

The application of coping to tinnitus research is fraught with a spectrum of issues that range from differing coping definitions to not directly measuring coping or not using psychometrically sound measurement instruments, which has resulted in a fragmented understanding of coping with tinnitus. Further, if researchers publish articles on coping with tinnitus using scales with unstable or unknown factor structures without first exploring the factor structure of the questionnaire relative to their sample, then all subsequent analyses, results, and interpretations should be viewed with caution.

The following are suggestions for researchers who are planning studies on tinnitus that include coping strategies:

1. When using a tinnitus-related coping instrument (e.g., Budd and Pugh's Tinnitus Coping Style Questionnaire or Henry and Wilson's TCSQ) to assess coping with tinnitus, researchers are strongly advised to conduct an exploratory (not confirmatory) factor analysis of their sample's data in order to examine the number of coping factors that are represented. Budd and Pugh's Tinnitus Coping Style Questionnaire, to date, has an unstable factor structure based on their sample's responses, whereas Henry and Wilson's TCSQ does not provide information about the actual types of coping strategies that are used, only frequency of coping use and its perceived effectiveness.

2. If researchers predict that their sample size will be too small to meet the minimum sample size for conducting a factor analysis according to generally accepted standards [71-72], then it is advisable to use one of the psychometrically sound coping instruments from the general field of coping, such as the Ways of Coping Checklist [73-74] or the Brief COPE [75]. Further, the coping scale should be anchored directly to coping with the stress of tinnitus by making it clear in the instrument's instructions that subjects should provide answers about how they respond to tinnitus-related stress and not general life stress or even stress related to their hearing difficulties.

3. Conducting a factor analysis of a scale, such as Budd and Pugh's Tinnitus Coping Style Questionnaire, in each research study can help researchers group coping strategies into content-related categories (e.g., problemsolving coping, emotion-focused coping) that are specific to their sample, which in turn can facilitate understanding the data, e.g., by identifying distinctive 
associations between distress and different types of coping.

4. Researchers should ensure that they are making clear conceptual distinctions between the constructs of coping and adaptation, given that these definitions have been used interchangeably in the tinnitus literature.

5. Coping should not be represented by changes on scales that measure negative affectivity (e.g., anxiety or depression scales), but should be measured directly by psychometrically sound coping instruments.

6. The variable of time or the temporal aspect of coping should be considered in research on coping with tinnitus in view of the aforementioned findings of Littleton et al.'s meta-analysis on coping strategies [24]. Their meta-analysis confirmed the trend noted in Suls and Fletcher's meta-analysis [31], indicating that while avoidant coping strategies may decrease stress in recent-onset conditions, coping strategies that directly approach or confront problematic conditions, situations, or events were found to be more effective in reducing stress in a long-term manner. Livneh also provided an in-depth exploration of the temporal aspects of coping strategies [36]. This line of research suggests that when individuals have chronic impairment, they may often face new challenges for which they do not yet have automatic responses; thus, they will utilize a variety of coping strategies during the gradual process of adapting to their chronic impairment. It should be expected that the use of specific coping strategies will vary over time (e.g., an individual with tinnitus might use avoidant coping when first dealing with tinnitus and later use an approach coping strategy, such as problem-solving).

7. Researchers should consider creating coping interventions or using existing ones, such as CET [18], that specifically promote and teach the use of coping skills, especially for individuals who are facing stress from chronic impairments such as tinnitus. While some interventions for tinnitus, such as TRT [13-14,76] and Progressive Tinnitus Management (PTM) (which uses CBT [15-17]), may have components that teach coping skills, they include a focus on changing individuals' perspectives about stress (e.g., TRT's reclassifying negative stimuli to neutral stimuli or CBT's addressing cognitive distortions). Coping interventions typically do not attempt to alter individuals' perspectives on stress but instead attempt to build individuals' skills in understanding and managing different types of stress.
Thus, coping interventions should include both stress management and problem-solving components in order to teach a range of more effective coping skills. The use of coping interventions, such as CET, in the context of tinnitus may help individuals realize that while some aspects of their lives are unchangeable (e.g., tinnitus), they can utilize a variety of coping strategies to modify the stressors that are changeable.

\section{Future Research}

We have adapted a specific coping intervention for individuals with tinnitus. The intervention is called CET and is a psycho-educational group intervention that targets coping skills. Chesney and Folkman created CET in 1994 [18] and grounded it in Lazarus and Folkman's theory of stress and coping [20]. Chesney et al. emphasized that CET teaches a framework for choosing among coping strategies and fitting the coping strategy to the changeability of an event [77]. CET specifically focuses on teaching individuals about stress and coping, problemsolving, matching the type of coping strategy with the type of stressor (categorized as changeable vs unchangeable), and using social support as a form of coping. Chesney and Folkman noted that CET also combines stress management techniques with a unique component of "a meta-strategy for choosing among coping strategies to maximize effectiveness in managing stressful situations and reducing stress. The meta-strategy converts the major tenets of stress and coping theory into action" [18 (p. 173)]. CET focuses on helping individuals choose the most appropriate type of coping for a particular type of stressor, which is one reason why CET is distinct from CBT interventions. Numerous clinical studies have been conducted using CET [37,77-80], which suggest that the CET intervention can help to reduce distress and improve coping among individuals with several types of chronic conditions and disabilities.

Chesney and Folkman's CET intervention has been adapted for tinnitus (in consultation with Dr. Chesney), and we are now testing it in a pilot study that compares a CET psycho-educational group intervention to a CBT psycho-educational group, an Acceptance and Commitment Therapy [81-82] psycho-educational group for tinnitus, and a usual-care group. This research is being conducted in the context of the PTM program [15-17]. PTM, which is endorsed by the Department of Veterans Affairs (VA), currently utilizes components of CBT as the psychological component of the intervention. 


\section{CONCLUSIONS}

At the present time, the research on coping with tinnitus (in both the areas of coping assessments and coping interventions) is fragmented because of a variety of theoretical, methodological, and statistical choices made by researchers. The purpose of this article was to highlight some of the problematic issues in the research on coping with tinnitus, as well as to suggest some approaches for researchers who plan to conduct research on coping with tinnitus, in order to help reduce discordant findings in future research.

Coping should be an essential construct in tinnitus research because for many individuals with tinnitus, it is a chronic stressor from which they cannot escape. As Wilson et al. asserted about coping with tinnitus: "the fact remains that learning to live with the problem or coping with the problem is precisely what people need to be able to do" [83 (p. 282)]. Helping individuals learn how to better cope with tinnitus may bring relief to those who experience significant distress and suffering because of their tinnitus.

\section{ACKNOWLEDGMENTS}

\author{
Author Contributions: \\ Concept and design: E. Martz. \\ Drafting of manuscript: E. Martz. \\ Critical revision of manuscript for important intellectual content: \\ E. Martz, J. A. Henry. \\ Project supervision: J. A. Henry.
}

Financial Disclosures: The authors have declared that no competing interests exist.

Funding/Support: This material was based on work supported by VA Rehabilitation Research and Development Service, Small Projects in Rehabilitation Research (SPiRE) (award C1578-P).

Additional Contributions: We would like to thank Dr. Hanoch Livneh, Portland State University, for providing feedback on an earlier version of this manuscript.

\section{REFERENCES}

1. Livneh H, Antonak RF. Psychosocial adaptation to chronic illness and disability: Gaithersburg (MD): Aspen Publishers; 1997.

2. Chan F, Da Silva-Cardoso E, Chronister JA, editors. Understanding psychosocial adjustment to chronic illness and disability: A handbook for evidence-based practitio- ners in rehabilitation. New York (NY): Springer Publishing Co; 2009.

3. Livneh H, Martz E. Adjustment to chronic illness and disabilities: Theoretical perspectives, empirical findings, and unresolved issues. In: Kennedy P, editor. The Oxford handbook of rehabilitation psychology. Oxford (UK): Oxford University Press; 2012.

4. Chwastiak L, Ehde DM, Gibbons LE, Sullivan M, Bowen JD, Kraft GH. Depressive symptoms and severity of illness in multiple sclerosis: Epidemiologic study of a large community sample. Am J Psychiatry. 2002;159(11):1862-68.

[PMID:12411220]

http://dx.doi.org/10.1176/appi.ajp.159.11.1862

5. Druss BG, Marcus SC, Rosenheck RA, Olfson M, Tanielian T, Pincus HA. Understanding disability in mental and general medical conditions. Am J Psychiatry. 2000; 157(9):1485-91. [PMID:10964866]

http://dx.doi.org/10.1176/appi.ajp.157.9.1485

6. Ormel J, VonKorff M, Ustun TB, Pini S, Korten A, Oldehinkel T. Common mental disorders and disability across cultures. Results from the WHO Collaborative Study on Psychological Problems in General Health Care. JAMA. 1994;272(22):1741-48. [PMID:7966922] http://dx.doi.org/10.1001/jama.1994.03520220035028

7. Turner RJ, Noh S. Physical disability and depression: A longitudinal analysis. J Health Soc Behav. 1988;29(1):23-37. [PMID:2966841] http://dx.doi.org/10.2307/2137178

8. McCormack A, Edmondson-Jones M, Fortnum H, Dawes $\mathrm{PD}$, Middleton H, Munro KJ, Moore DR. Investigating the association between tinnitus severity and symptoms of depression and anxiety, while controlling for neuroticism, in a large middle-aged UK population. Int J Audiol. 2015; 54(9):599-604. [PMID:25766493] http://dx.doi.org/10.3109/14992027.2015.1014577

9. Gomaa MA, Elmagd MH, Elbadry MM, Kader RM. Depression, Anxiety and Stress Scale in patients with tinnitus and hearing loss. Eur Arch Otorhinolaryngol. 2014; 271(8):2177-84. [PMID:24071860] http://dx.doi.org/10.1007/s00405-013-2715-6

10. Zeman F, Koller M, Langguth B, Landgrebe M; Tinnitus Research Initiative database study group. Which tinnitusrelated aspects are relevant for quality of life and depression: Results from a large international multicentre sample. Health Qual Life Outcomes. 2014;12:7.

[PMID:24422941] http://dx.doi.org/10.1186/1477-7525-12-7

11. Martz E, Livneh H, editors. Coping with chronic illness and disability: Theoretical, empirical, and clinical aspects. New York (NY): Springer; 2007. 
12. Møller A. Epidemiology of tinnitus in adults. In: Møller A, Langguth B, DeRidder D, Kleinjung T, editors. Textbook of tinnitus. New York (NY): Springer; 2011. p. 29-37.

13. Jastreboff PJ. Tinnitus retraining therapy. In: Møller A, Langguth B, DeRidder D, Kleinjung T, editors. Textbook of tinnitus. New York (NY): Springer; 2011. p. 575-96.

14. Henry JA, Jastreboff MM, Jastreboff PJ, Schechter MA, Fausti SA. Guide to conducting tinnitus retraining therapy initial and follow-up interviews. J Rehabil Res Dev. 2003; 40(2):157-77. [PMID:15077641] http://dx.doi.org/10.1682/JRRD.2003.03.0159

15. Henry JA, Zaugg TL, Myers PM, Kendall CJ. Progressive tinnitus management: Counseling guide. San Diego (CA): Plural Publishing; 2010.

16. Henry JA, Zaugg TL, Myers PM, Kendall CJ. Progressive tinnitus management: Clinical handbook for audiologists. San Diego (CA): Plural Publishing; 2010.

17. Henry JA, Zaugg TL, Schechter MA, Myers PJ. How to manage your tinnitus: A step-by-step workbook. Portland (OR): VA National Center for Rehabilitative Auditory Research; 2008.

18. Chesney MA, Folkman S. Psychological impact of HIV disease and implications for intervention. Psychiatr Clin North Am. 1994;17(1):163-82. [PMID:8190663]

19. Zeidner M, Endler N, editors. Handbook of coping: Theory, research, applications. Oxford (UK): John Wiley \& Sons; 1996.

20. Lazarus R, Folkman S. Stress, coping and adaptation. New York (NY): Springer; 1984.

21. Livneh H. Psychosocial adaptation to chronic illness and disability - A conceptual framework. Rehabil Couns Bull. 2001;44:151-60. http://dx.doi.org/10.1177/003435520104400305

22. Costa PT Jr, Somerfield MR, McCrae RR. Personality and coping: A reconceptualization. In: Zeidner M, Endler N, editors. Handbook of coping: Theory, research, applications. Oxford (UK): John Wiley \& Sons; 1996. p. 44-61.

23. Folkman S, Moskowitz JT. Coping: Pitfalls and promise. Annu Rev Psychol. 2004;55:745-74. [PMID:14744233] http://dx.doi.org/10.1146/annurev.psych.55.090902.141456

24. Littleton H, Horsley S, John S, Nelson DV. Trauma coping strategies and psychological distress: A meta-analysis. J Trauma Stress. 2007;20(6):977-88. [PMID:18157893] http://dx.doi.org/10.1002/jts.20276

25. Andersson G, Willebrand $M$. What is coping? A critical review of the construct and its application in audiology. Int J Audiol. 2003;42(Suppl 1):S97-103. [PMID:12918616] http://dx.doi.org/10.3109/14992020309074630

26. Chronister J, Chan F. Hierarchical coping: A conceptual framework for understanding coping within the context of chronic illness and disability. In: Martz E, Livneh H, editors. Coping with chronic illness and disability: Theoreti- cal, empirical, and clinical aspects. New York (NY): Springer; 2007. p. 49-71.

27. Krohne H. Individual differences in coping. In: Zeidner M, Endler N, editors. Handbook of coping: Theory, research, applications. Oxford (UK): John Wiley \& Sons; 1996. p. 381-409.

28. Roth S, Cohen LJ. Approach, avoidance, and coping with stress. Am Psychol. 1986;41(7):813-19. [PMID:3740641] http://dx.doi.org/10.1037/0003-066X.41.7.813

29. Tobin DL, Holroyd KA, Reynolds RV, Wigal JK. The hierarchical factor structure of the Coping Strategies Inventory. Cogn Ther Res. 1989;13:343-61. http://dx.doi.org/10.1007/BF01173478

30. Krohne H. The concept of coping modes: Relating cognitive person variables to actual coping behavior. Adv Behav Res Ther. 1989;11:235-48. http://dx.doi.org/10.1016/0146-6402(89)90027-1

31. Suls J, Fletcher B. The relative efficacy of avoidant and nonavoidant coping strategies: A meta-analysis. Health Psychol. 1985;4(3):249-88. [PMID:4029107] http://dx.doi.org/10.1037/0278-6133.4.3.249

32. Skinner EA, Edge K, Altman J, Sherwood H. Searching for the structure of coping: A review and critique of category systems for classifying ways of coping. Psychol Bull. 2003;129(2):216-69. [PMID:12696840] http://dx.doi.org/10.1037/0033-2909.129.2.216

33. Bracken MB, Shepard MJ. Coping and adaptation following acute spinal cord injury: A theoretical analysis. Paraplegia. 1980;18(2):74-85. [PMID:6990353]

http://dx.doi.org/10.1038/sc.1980.13

34. Holahan CJ, Moos RH, Schaefer JA. Coping, stress resistance, and growth: Conceptualizing adaptive functioning. In: Zeidner M, Endler N, editors. Handbook of coping: Theory, research, applications. Oxford (UK): John Wiley \& Sons; 1996. p. 24-43.

35. Lazarus RS. Coping theory and research: Past, present, and future. Psychosom Med. 1993;55(3):234-47. [PMID:8346332] http://dx.doi.org/10.1097/00006842-199305000-00002

36. Livneh H. Quality of life and coping with chronic illness and disability: A temporal perspective. Rehabil Couns Bull. 2016;59(2):67-83.

37. Chesney MA, Chambers DB, Taylor JM, Johnson LM, Folkman S. Coping effectiveness training for men living with HIV: Results from a randomized clinical trial testing a group-based intervention. Psychosom Med. 2003;65(6): 1038-46. [PMID:14645783] http://dx.doi.org/10.1097/01.PSY.0000097344.78697.ED

38. Horowitz M. Stress response syndromes: PTSD, grief, and adjustment disorders. New York (NY): Jason Aronson; 1997.

39. Andersson G, Kaldo V, Strömgren T, Ström L. Are coping strategies really useful for the tinnitus patient? An investigation 
conducted via the internet. Audiological Med. 2004;2:5459.

http://dx.doi.org/10.1080/16513860410027358

40. Budd RJ, Pugh R. Tinnitus coping style and its relationship to tinnitus severity and emotional distress. J Psychosom Res. 1996;41(4):327-35. [PMID:8971662] http://dx.doi.org/10.1016/S0022-3999(96)00171-7

41. Budd RJ, Pugh R. The relationship between coping style, tinnitus severity and emotional distress in a group of tinnitus sufferers. Br J Health Psychol. 1996;1:219-29. http://dx.doi.org/10.1111/j.2044-8287.1996.tb00504.x

42. Henry JL, Wilson PH. Coping with tinnitus: Two studies of psychological and audiological characteristics of patients with high and low tinnitus-related distress. Int Tinnitus J. 1995;1(2):85-92. [PMID:10753328]

43. Zachriat C, Kröner-Herwig B. Treating chronic tinnitus: Comparison of cognitive-behavioural and habituationbased treatments. Cogn Behav Ther. 2004;33(4):187-98. [PMID:15625793] http://dx.doi.org/10.1080/16506070410029568

44. Croft C, Brown RF, Thorsteinsson EB, Noble W. Development of the Tinnitus Response Scales: Factor analyses, subscale reliability and validity analyses. Int Tinnitus J. 2013; 18(1):45-56. [PMID:24995899]

http://dx.doi.org/10.5935/0946-5448.20130007

45. Sullivan MD, Katon W, Dobie R, Sakai C, Russo J, Harrop-Griffiths J. Disabling tinnitus. Association with affective disorder. Gen Hosp Psychiatry. 1988;10(4):285-91. [PMID:3417130] http://dx.doi.org/10.1016/0163-8343(88)90037-0

46. Vitaliano PP, Russo J, Carr JE, Maiuro RD, Becker J. The Ways of Coping Checklist: Revision and psychometric properties. Multivariate Behav Res. 1985;20(1):3-26. [PMID:26776273] http://dx.doi.org/10.1207/s15327906mbr2001_1

47. Derogatis L, Lipman R. SCL-90. Administration, scoring and procedures Manual I for the R(evised) version and other instruments of the psychopathology rating scale series. Chicago (IL): John Hopkins University School of Medicine; 1977.

48. Bartels H, Middel BL, van der Laan BF, Staal MJ, Albers FW. The additive effect of co-occurring anxiety and depression on health status, quality of life and coping strategies in help-seeking tinnitus sufferers. Ear Hear. 2008; 29(6):947-56. [PMID:18941410] http://dx.doi.org/10.1097/AUD.0b013e3181888f83

49. Zigmond AS, Snaith RP. The Hospital Anxiety and Depression Scale. Acta Psychiatr Scand. 1983;67(6):361-70. [PMID:6880820] http://dx.doi.org/10.1111/j.1600-0447.1983.tb09716.x

50. Wilson PH, Henry J, Bowen M, Haralambous G. Tinnitus Reaction Questionnaire: Psychometric properties of a mea- sure of distress associated with tinnitus. J Speech Hear Res. 1991;34(1):197-201. [PMID:2008074]

http://dx.doi.org/10.1044/jshr.3401.197

51. Andersson G, Lyttkens L. A meta-analytic review of psychological treatments for tinnitus. Br J Audiol. 1999;33(4): 201-10. [PMID:10509855] http://dx.doi.org/10.3109/03005369909090101

52. Martinez-Devesa P, Perera R, Theodoulou M, Waddell A. Cognitive behavioural therapy for tinnitus. Cochrane Database Syst Rev. 2010;(9):CD005233. [PMID:20824844]

53. Hesser H, Weise C, Westin VZ, Andersson G. A systematic review and meta-analysis of randomized controlled trials of cognitive-behavioral therapy for tinnitus distress. Clin Psychol Rev. 2011;31(4):545-53. [PMID:21237544] http://dx.doi.org/10.1016/j.cpr.2010.12.006

54. Hoare DJ, Kowalkowski VL, Kang S, Hall DA. Systematic review and meta-analyses of randomized controlled trials examining tinnitus management. Laryngoscope. 2011; 121(7):1555-64. [PMID:21671234] http://dx.doi.org/10.1002/lary.21825

55. Henry JL, Wilson PH. The psychological management of tinnitus: Comparison of a combined cognitive educational program, education alone and a waiting-list control. Int Tinnitus J. 1996;2:9-20. [PMID:10753339]

56. Kröner-Herwig B, Hebing G, van Rijn-Kalkmann U, Frenzel A, Schilkowsky G, Esser G. The management of chronic tinnitus - Comparison of a cognitive-behavioural group training with yoga. J Psychosom Res. 1995;39(2):153-65. [PMID:7595873] http://dx.doi.org/10.1016/0022-3999(94)00098-P

57. Kröner-Herwig B, Frenzel A, Fritsche G, Schilkowsky G, Esser G. The management of chronic tinnitus: Comparison of an outpatient cognitive-behavioral group training to minimal-contact interventions. J Psychosom Res. 2003; 54(4):381-89. [PMID:12670617] http://dx.doi.org/10.1016/S0022-3999(02)00400-2

58. Frenzel A. Chronischer Tinnitus: Evaluation eines kognitiv-behavioralen Gruppentrainings und einer Minimalintervention. Herdecke: GCA-Verlag; 1998. German.

59. Sirois FM, Davis CG, Morgan MS. "Learning to live with what you can't rise above": Control beliefs, symptom control, and adjustment to tinnitus. Health Psychol. 2006; 25(1):119-23. [PMID:16448305]

http://dx.doi.org/10.1037/0278-6133.25.1.119

60. Scott B, Lindberg P, Lyttkens L, Melin L. Psychological treatment of tinnitus. An experimental group study. Scand Audiol. 1985;14(4):223-30. [PMID:3912955] http://dx.doi.org/10.3109/01050398509045945

61. Andersson G, Kaldo V. Internet-based cognitive behavioral therapy for tinnitus. J Clin Psychol. 2004;60(2):171-78. [PMID:14724924] http://dx.doi.org/10.1002/jclp.10243 
62. Wise K, Rief W, Goebel G. Meeting the expectations of chronic tinnitus patients: Comparison of a structured group therapy program for tinnitus management with a problemsolving group. J Psychosom Res. 1998;44(6):681-85.

[PMID:9678749]

http://dx.doi.org/10.1016/S0022-3999(97)00310-3

63. Caffier PP, Haupt H, Scherer H, Mazurek B. Outcomes of long-term outpatient tinnitus-coping therapy: Psychometric changes and value of tinnitus-control instruments. Ear Hear. 2006;27(6):619-27. [PMID:17086074] http://dx.doi.org/10.1097/01.aud.0000240504.77861.1a

64. Hesser H, Gustafsson T, Lundén C, Henrikson O, Fattahi K, Johnsson E, Zetterqvist Westin V, Carlbring P, MäkiTorkko E, Kaldo V, Andersson G. A randomized controlled trial of Internet-delivered cognitive behavior therapy and acceptance and commitment therapy in the treatment of tinnitus. J Consult Clin Psychol. 2012;80(4):649-61.

[PMID:22250855]

http://dx.doi.org/10.1037/a0027021

65. Hiller W, Haerkötter C. Does sound stimulation have additive effects on cognitive-behavioral treatment of chronic tinnitus? Behav Res Ther. 2005;43(5):595-612.

[PMID:15865915]

http://dx.doi.org/10.1016/j.brat.2004.03.012

66. Lindberg P, Scott B, Melin L, Lyttkens L. Behavioural therapy in the clinical management of tinnitus. Br J Audiol. 1988;22(4):265-72. [PMID:3242716] http://dx.doi.org/10.3109/03005368809076463

67. Westin VZ, Schulin M, Hesser H, Karlsson M, Noe RZ, Olofsson U, Stalby M, Wisung G, Andersson G. Acceptance and commitment therapy versus tinnitus retraining therapy in the treatment of tinnitus: A randomised controlled trial. Behav Res Ther. 2011;49(11):737-47. [PMID:21864830] http://dx.doi.org/10.1016/j.brat.2011.08.001

68. Hallberg L, Erlandsson S, Carlsson S. Coping strategies used by middle-aged males with noise-induced hearing loss, with and without tinnitus. Psychol Health. 1992;7: 273-88. http://dx.doi.org/10.1080/08870449208403157

69. Philippot P, Nef F, Clauw L, de Romrée M, Segal Z. A randomized controlled trial of mindfulness-based cognitive therapy for treating tinnitus. Clin Psychol Psychother. 2012;19(5):411-19. [PMID:21567655] http://dx.doi.org/10.1002/cpp.756

70. Meikle MB, Henry JA, Griest SE, Stewart BJ, Abrams HB, McArdle R, Myers PJ, Newman CW, Sandridge S, Turk DC, Folmer RL, Frederick EJ, House JW, Jacobson GP, Kinney SE, Martin WH, Nagler SM, Reich GE, Searchfield G, Sweetow R, Vernon JA. The Tinnitus Functional Index: Development of a new clinical measure for chronic, intrusive tinnitus. Ear Hear. 2012;33(2):153-76.

[PMID:22156949]

http://dx.doi.org/10.1097/AUD.0b013e31822f67c0
71. Tabachnick B, Fidell L. Using multivariate statistics. Boston (MA): Pearson Education Inc; 2007.

72. MacCallum R, Widaman K, Zhang S, Hong S. Sample size in factor analysis. Psychol Methods. 1999;4:84-99. http://dx.doi.org/10.1037/1082-989X.4.1.84

73. Folkman S, Lazarus R. Manual for the Ways of Coping Questionnaire. Sunnyvale (CA): Consulting Psychologists Press; 1988.

74. Folkman S, Lazarus RS. If it changes it must be a process: Study of emotion and coping during three stages of a college examination. J Pers Soc Psychol. 1985;48(1):150-70. [PMID:2980281] http://dx.doi.org/10.1037/0022-3514.48.1.150

75. Carver CS. You want to measure coping but your protocol's too long: Consider the Brief COPE. Int J Behav Med. 1997;4(1):92-100. [PMID:16250744] http://dx.doi.org/10.1207/s15327558ijbm0401_6

76. Jastreboff PJ, Jastreboff MM. Tinnitus Retraining Therapy (TRT) as a method for treatment of tinnitus and hyperacusis patients. J Am Acad Audiol. 2000;11(3):162-77. [PMID:10755812]

77. Chesney M, Folkman S, Chambers D. Coping effectiveness training for men living with HIV: Preliminary findings. Int J STD AIDS. 1996;7(Suppl 2):75-82. [PMID:8799801] http://dx.doi.org/10.1258/0956462961917690

78. King C, Kennedy P. Coping effectiveness training for people with spinal cord injury: Preliminary results of a controlled trial. Br J Clin Psychol. 1999;38(Pt 1):5-14. [PMID:10212733]

79. Kennedy P, Duff J, Evans M, Beedie A. Coping effectiveness training reduces depression and anxiety following traumatic spinal cord injuries. Br J Clin Psychol. 2003; 42(Pt 1):41-52. [PMID:12675978]

80. Duchnick JJ, Letsch EA, Curtiss G. Coping effectiveness training during acute rehabilitation of spinal cord injury/ dysfunction: A randomized clinical trial. Rehabil Psychol. 2009;54(2):123-32. [PMID:14724924] http://dx.doi.org/10.1037/a0015571

81. Hayes S, Strosahl K, Wilson K. Acceptance and commitment therapy: An experiential approach to behavior change. New York (NY): Guilford Press; 1999.

82. Hayes S, Strosahl K, Wilson K. Acceptance and commitment therapy: The process and practice of mindful change. New York (NY): Guilford Press; 2011.

83. Wilson PH, Henry JL, Andersson G, Hallam RS, Lindberg P. A critical analysis of directive counselling as a component of tinnitus retraining therapy. Br J Audiol. 1998;32(5): 273-86. [PMID:9845025] http://dx.doi.org/10.3109/03005364000000078

Submitted for publication September 15, 2015. Accepted in revised form January 29, 2016. 
JRRD, Volume 53, Number 6, 2016

This article and any supplementary material should be cited as follows:

Martz E, Henry JA. Coping with tinnitus. J Rehabil Res
Dev. 2016;53(6):729-42.

http://dx.doi.org/10.1682/JRRD.2015.09.0176

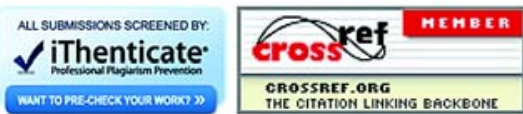

